\title{
Impression of South Korea and Korean Health Care from a Visitor
}

\author{
Ashley Yi-Fang Lee \\ Department of Health Policy and Management, Gillings School of Global Public Health , \\ The University of North Carolina at Chapel Hill
}

As a graduate student studying in the US and originally from Taiwan, my experience here in South Korea has been fantastic from the very moment I stepped off the plane. The airport is extremely well organized and connected to downtown Seoul by public transportation. The transit system in Seoul is, as I have learned, extremely awesome. Every station is provided with clear directional signs showing exactly where the exits are and where they lead. The city is beautifully harmonized with traditional and modern flavor. In the central Seoul city, you can find the hundreds-year-old UNESCO World Heritage palace, which is famous for its outstanding architectural details. In the meantime, Seoul has everything innovative you could expect in an urban capital city. People living in Seoul take great pride in their centuries-old city. The pride in a culture and a unique language leads to a strong national identity. Like the food style here in Korea, people are very heart-warming. Koreans seem to be in touch with their emotions more than westerners. You often see young and old, boys and girls holding hands, hugging or collectively sharing in a colleague's grief or joy. I find this aspect of their culture truly charming.

Korea has gone to a health care system characterized by universal coverage and one of the highest life expectancies in the world, while still having one of the lowest levels of health expenditure among OECD countries. The quality of Korean people's lives has been increasingly improved in general due to the development of medical technology. Given the chance to learn the culture and traits of Korean, I have some observations upon the visits in hospitals in Seoul.

Growing up in Taipei, Taiwan, I am unsurprised with the incredible efficiency in hospitals, short waittime, and easily accessible care in Asia comparing to western countries. However, the efficiency in Seoul has surprised me to the next level. This is possibly attributed to the following reasons. First, the multiple 
reception counters in front of specialty departments help preventing the long queue. I found this incredibly useful in diminishing unnecessary waits on administrative procedures, moreover, the hospital lobby would not be overwhelmed by visitors even in a high-volume medical center. Second, Korea has developed a strong information technology capacity in various industries. Health care institutes in Korea also take good advantage of the technology. The electronic kiosks could be easily found within the outpatient departments. With straightforward interface, you can check in before the scheduled appointment or make the payment by the machine simply entering your identification number. The same technology also appears in many restaurants and café that I only need to spend negligible time to order. I strongly believe there are many more innovative high-tech facilities I did not discover yet. Lastly, under the current structure, most practitioners need to take care of many patients as possible in order to increase the margin or to reduce the loss. Along with the growing patient volume, efficiency plays a crucial role while pursing the improvements on quality of care and maintaining patient satisfaction. Other than the factor above, being productive, as one of the characteristics of Korean, may also explained the current state of efficiency. Korean, especially those live in a major city like Seoul, are less willing to spend time waiting and they want to do as many things as possible in a short period of time. The Pali pali (in English this means hurry hurry) culture revolves around the idea of getting things done as fast as possible. This is also evidenced in the remarkable speedy food delivery in Korea. In 2016, the national health expenditure of South Korea was projected to account for approximately 7.7 percent of the total GDP. Aside from the one-payer system as the primary reason of low health expenditure, the efficiency could also be one of the contributors in sustaining affordable care for Korean citizens.

With continuous reforms, the national health insurance has become deeply rooted in Korean society and strongly support the nation. It has been more than thirty years since the national health insurance program was implemented in Korea. It was only twelve years that Korean National Health Insurance took to reach Universal Healthcare Coverage (UHC). UHC provides people access to the health care services they need without undue financial hardship. The quality and general satisfaction of Korean healthcare has consistently been one of the best in the world, comparing with other OECD countries. These were all resulted by the efforts of the government, medical society and the people of Korea. From my observation, Korean work incredibly long hours compared to western standards. It is probably the relentless dedication and commitment to the country that Korea achieves a good-quality, affordable and efficient health care system. 